\title{
Transcatheter versus surgical treatment for aortic stenosis: Patient selection and early outcome
}

\author{
Carl-Fredrik Appel, Henrik Hultkvist, Eva Nylander, Henrik Casimir Ahn, \\ Niels Erik Nielsen, Wolfgang Freter and Farkas Vánky
}

\section{Linköping University Post Print}

N.B.: When citing this work, cite the original article.

Original Publication:

Carl-Fredrik Appel, Henrik Hultkvist, Eva Nylander, Henrik Casimir Ahn, Niels Erik Nielsen, Wolfgang Freter and Farkas Vánky, Transcatheter versus surgical treatment for aortic stenosis: Patient selection and early outcome, 2012, Scandinavian Cardiovascular Journal, (46), 5, 301-307.

http://dx.doi.org/10.3109/14017431.2012.699636

Copyright: Informa Healthcare

http://informahealthcare.com/

Postprint available at: Linköping University Electronic Press http://urn.kb.se/resolve?urn=urn:nbn:se:liu:diva-84532 
C. Appel et al.

\section{Transcatheter vs surgical treatment for aortic stenosis; patient}

selection and early outcome

CARL-FREDRIK APPEL ${ }^{1}$, HENRIK HULTKVIST ${ }^{1}$ MD, EVA NYLANDER ${ }^{2}$ MD PROF, HENRIK AHN ${ }^{1}$ MD PROF, NIELS E NIELSEN ${ }^{3}$ MD PHD, WOLFGANG FRETER ${ }^{4}$ MD \& FARKAS VÁNKY ${ }^{1}$ MD PHD

${ }^{1}$ Dept of Cardiothoracic and Vascular Surgery, ${ }^{2}$ Dept of Clinical Physiology, ${ }^{3}$ Dept of Cardiology, ${ }^{4}$ Dept of Cardiothoracic Anesthesia, County Council of Östergötland, Linköping, and Division of Cardiovascular Medicine, Department of Medicine and Health Sciences, Faculty of Health Sciences, Linköping University, Sweden

Short title: Short term outcome after TAVI and SAVR

Correspondence: Dr Farkas Vánky, Dept. of Cardiothoracic and Vascular Surgery, Linköping Heart Center, University Hospital, SE-581 85 Linköping, Sweden. Phone: + 46101030128 Fax: + 46131002 46. E-mail: farkas.vanky@lio.se 


\section{ABSTRACT}

Objectives. To describe short-term clinical and echocardiography outcomes in patients undergoing transcatheter aortic valve implantation (TAVI) and surgical aortic valve replacement (SAVR). To explore patient selection criteria for treatment with TAVI.

Design. TAVI patients $(n=45)$ were matched to SAVR patients $(n=45)$ with respect to age within \pm 10 years, sex and systolic left ventricular function.

Results. TAVI patients were older, $82 \pm 8$ vs. $78 \pm 5$ years $(\mathrm{p}=0.005)$ and they had higher $\operatorname{logEuroSCORE}, 16 \pm 11 \%$ vs. $8 \pm 4 \%$ ( $\mathrm{p}<0.001)$. There were no significant differences in 30 day mortality, stroke and myocardial infarction. TAVI patients received less erythrocyte (53\% vs. $78 \%, \mathrm{p}=0.03)$ and thrombocyte $(7 \%$ vs. $27 \%, \mathrm{p}=0.02)$ transfusions. Postoperative atrial fibrillation was less common $(18 \%$ vs. $60 \%, \mathrm{p}<0.001)$ in the TAVI group. Paravalvular regurgitation was more common in TAVI patients $(87 \%$ vs. $0 \%, \mathrm{p}<0.001)$ and $27 \%$ had access site complications. Aortic transvalvular velocity was $2.3 \pm 0.4 \mathrm{~m} / \mathrm{s}$ vs. $2.6 \pm 0.5 \mathrm{~m} / \mathrm{s}$ $(\mathrm{p}=0.002)$ and mean valve pressure gradient was $12 \pm 4 \mathrm{mmHg}$ vs. $15 \pm 5 \mathrm{mmHg},(\mathrm{p}=0.01)$ in the TAVI and SAVR groups respectively. Twenty-nine (64\%) of the TAVI patients had $\log$ EuroSCORE $<15 \%$.

Conclusions. Both TAVI and SAVR have good short term clinical outcome with excellent hemodynamic result. In clinical practice, factors other than high logEuroSCORE play an important role in patient selection for TAVI.

Key words: transcatheter aortic valve implantation, aortic valve replacement, outcome, echocardiography, patient selection 
C. Appel et al.

\section{INTRODUCTION}

Aortic stenosis (AS) is the most common valvular disease found in developed countries and its prevalence increases with age (1). The survival with medical treatment of symptomatic aortic stenosis is poor and surgical aortic valve replacement (SAVR) is advised in patients with symptomatic aortic stenosis, according to current guidelines (1-3). Reports on SAVR show an excellent short and long term outcome with current patient selection (4-6). However, a variety of factors, such as increasing age, poor left ventricular function, renal dysfunction, anemia, low body mass index, pulmonary hypertension and cerebrovascular disease have been identified to increase surgical mortality and morbidity $(4,6-8)$. Some patients also present with technical difficulties like heavily calcified ascending aorta, patent coronary grafts after previous cardiac surgery or sequelae of chest radiation that make SAVR challenging (9). Since the first percutaneous transcatheter aortic valve implantation (TAVI) procedure in human in 2002 described by Cribier et al. (10), TAVI techniques have developed to provide an alternative approach in patients for whom SAVR infers an unacceptable high risk (9). Because TAVI is a new therapy its procedural outcome needs to be evaluated in relation to SAVR (11). To optimize the benefit of TAVI, objective patient selection criteria for TAVI have to be established.

The aim of this study was to describe short-term clinical outcomes, echocardiographic results and 6-months mortality in two groups of matched patients undergoing TAVI and SAVR, respectively. In addition, we wanted to analyze factors influencing the choice of TAVI as treatment for aortic stenosis. 
C. Appel et al.

\section{MATERIAL AND METHODS}

\section{Study design}

At the introduction of TAVI at Linköping University Hospital a prospective, descriptive study, including TAVI and SAVR patients, was designed to evaluate the patients undergoing TAVI in relation to a matched group of patients undergoing SAVR. The study was approved by the Regional Ethical Review Board in Linköping, Sweden and informed, written consent was obtained.

\section{Patients}

At our center, serving a population of approximately one million, patients with symptomatic aortic stenosis accepted for SAVR or TAVI were continuously recruited to the study population. A team of cardiologists and cardiac surgeons reviewed and accepted patients for SAVR or for TAVI. TAVI was primly considered in case of high surgical risk in terms of predicted mortality with logistic European System for Cardiac Operative Risk Evaluation $(\operatorname{logEuroSCORE})>15 \%(12)$. Patients with $\log$ EuroSCORE $<15 \%$ were not excluded from treatment with TAVI in the presence of factors which made treatment with TAVI preferable in the opinion of the decision board. Table 1.

Only patients with calcific AS and a hinge-point diameter within the range of 18 to $25 \mathrm{~mm}$ were accepted for TAVI. The transfemoral access route was preferred. In case computer tomography verified severe iliofemoral arterial disease or $<7-8 \mathrm{~mm}$ diameter of the common femoral artery (depending on the TAVI valve size), the transapical approach was chosen. During the study period, a total of 62 patients underwent TAVI and 45 agreed to take part in the study. Transfemoral approach was chosen in 29 patients and transapical in 16 patients. 
Forty-five SAVR, operated during the same period for AS, were matched regarding age within a range of \pm 10 years, sex and systolic left ventricular function divided into two groups, normal to mildly impaired and moderately to severely impaired. Patients undergoing SAVR were not included in case of multiple coronary artery disease, i.e. more than one vessel disease, or concurrent surgery of the mitral valve. None of the patients undergoing percutaneous replacement of the aortic valve was converted to SAVR. Clinical follow-up and echocardiography were performed 3 to 5 days postprocedurally. Data were recorded in the clinical database Carath (Fujitsu Ltd, Tokyo, Japan) and variables used were double checked with clinical records.

\section{Demographics}

\section{TAVI}

Mean age was $81 \pm 8$ years (range 60 to 92 years). Left ventricular ejection fraction was normal, mildly, moderately and severely impaired in $32(71 \%), 10(22 \%), 2(4 \%)$ and $1(2 \%)$ of the patients respectively. Mean logEuroSCORE was $16 \pm 11 \%$ and the Society of Thoracic Surgeons score was $4.4 \pm 2.3$.

\section{SAVR}

Mean age was $77 \pm 5$ years (range 60 to 85 years). Left ventricular ejection fraction was normal, mildly, moderately and severely impaired in $39(87 \%), 3(7 \%), 3(7 \%)$ and $0(0 \%)$ of the patients respectively. Mean logEuroSCORE was $8 \pm 4 \%$ and the Society of Thoracic Surgeons score was 3.0 \pm 1.3. Detailed baseline characteristics for the TAVI and AVR groups are shown in Table 2.

\section{Procedures}

TAVI 
C. Appel et al.

Procedures were performed in our hybrid laboratory under general anesthesia with endotracheal intubation. A dedicated team of cardiac interventionists, cardiac surgeons and cardiac anesthesiologists performed all procedures.

The aortic annulus diameter was measured with transesophageal echocardiography (TEE) and a 23- or 26-mm, expanded size, Edwards Sapien valve bioprosthesis (Edwards Lifesciences Inc, Irvine, Calif) was used for implantation $(13,14)$. Before implantation the stent valve was mechanically crimped onto a balloon catheter. During transfemoral procedures, vascular access was obtained with percutaneous puncture of the femoral artery. Through the opposite femoral artery a pigtail catheter was placed in the aortic root. On the same side the femoral vein was punctured and a 6 Fr introducer was inserted to secure venous access in case of intraprocedural haemodynamic instability requiring extra cardiopulmonary bypass (CPB) support. Balloon valvuloplasty, followed by implantation of the valve during rapid right ventricular burst pacing, was performed according to standard TAVI procedure routine. TEE and fluoroscopy in preselected views guided by transthoracic echocardiography according to an in-house developed procedure reduced the need for angiography at this step (15). Femoral access point was in the majority of cases closed with percutaneous sutures (Perclose ${ }^{\circledR}$ ProGlide ${ }^{\mathrm{TM}}$, Abbot Vascular, Calif), but in some cases surgical cut down was needed. The prosthetic valve function was evaluated with TEE before patient was taken to the intensive care unit

During transapical procedures a minimal left-sided thoracotomy was performed, the pericardium opened, purse string sutures applied, and an apical needle puncture was performed. After valve deployment the puncture site of the left ventricle and the thoracotomy were surgically closed. 
C. Appel et al.

\section{SAVR}

The patients underwent surgery using standard techniques with cardiopulmonary bypass (CPB) and aortic cross clamping. Ringer's acetate and mannitol was used for priming the extracorporeal circuit. Moderate hemodilution (hematocrit 20-25\%) and mild hypothermia $\left(33-36{ }^{\circ} \mathrm{C}\right)$ were usually employed. Antegrade $(18 \%)$ or combined ante- and retrograde $(82 \%)$ delivery of a cold blood cardioplegia were used for myocardial protection. Weaning from $\mathrm{CPB}$ was started at a rectal temperature of $35-36{ }^{\circ} \mathrm{C}$. Heparin was neutralized with protamine chloride.

\section{Statistical analysis}

Categorical variables are presented as numbers and frequencies and continuous variables as means \pm standard deviation. Nonparametric statistical calculations were performed on all variables. Fischer's exact test was used for comparison of categorical variables and MannWhitney-U test was used for continuous variables. A value of $p<0.05$ was considered statistically significant. STATISTICA 9.0 (StatSoft Inc., Tulsa, Okla) was used for all statistical analyses.

\section{RESULTS}

\section{TAVI}

Procedure time was $127 \pm 42 \mathrm{~min}$. and one patient needed CPB support for $35 \mathrm{~min}$. All stent valve implantations were successful with no conversion to open surgery. Seventeen patients had a $23 \mathrm{~mm}$ and 28 patients a $26 \mathrm{~mm}$ stent valve. 
C. Appel et al.

\section{SAVR}

CPB-time was $97 \pm 35 \mathrm{~min}$. and cross-clamp time $68 \pm 18 \mathrm{~min}$. Simultaneous procedures were CABG in 9 patients (20\%) and tricuspid valve annuloplasty in one patient (2\%). All patients received biologic aortic valve prosthesis. The Perimount 2900 aortic valve prosthesis (Edwards Lifesciences Inc, Irvine, Calif), the Hancock II Aortic valve prosthesis (Medtronic Ltd. Minneapolis, Minn) and the Freestyle aortic valve prosthesis (Medtronic Ltd. Minneapolis, Minn) were used. Prosthesis sizes were $19 \mathrm{~mm}$ in 8 patients, $21 \mathrm{~mm}$ in 12 patients, $23 \mathrm{~mm}$ in 17 patients and $25 \mathrm{~mm}$ in 8 patients.

\section{Procedural outcome}

In the TAVI group 12 patients (27\%) had periprocedural access site complications. Out of these, $8(18 \%)$ patients had femoral artery bleeding. Two patients $(4 \%)$ had bleeding from the apical portion of the heart. Both died from AMI and respiratory/cardiac failure at day 2 and 15 , respectively. One patient had iliac dissection with subsequent vascular repair and died after 106 days due to leg ischemia and exacerbations of chronic obstructive pulmonary disease. In one patient the femoral artery was occluded and required surgery, development of acute compartment syndrome and fasciotomy followed.

Severe circulatory failure after rapid pacing occurred in $3(7 \%)$ patients. Heart compressions were given in two cases for 5 and 22 minutes respectively and the latter was followed by 35 minutes of CPB support. Both patients became circulatory stable but the one needing CPB support died at day 6 due to multi organ failure. In the third patient circulatory failure was pharmacologically treated. Acute intraoperative hemopericardium of hemodynamic 
significance occurred in one patient and was successfully treated with percutaneous pericardial drainage.

Postoperative pericardial tamponade, compromising cardiac function occurred in $3(7 \%)$ patients and they were treated with pericardial drainage. One of these died from multiorgan failure due to the combination of liver bleeding, aspiration pneumonia and AMI.

In the group of patients undergoing SAVR, $4(9 \%)$ patients became circulatory unstable after disconnecting CPB requiring measurements such as inotropic treatment and in one case treatment with intra-aortic balloon pump. In one of the circulatory unstable patients, right coronary artery (RCA) dysfunction called for coronary grafting which resulted in recovery of the right ventricular function.

\section{Clinical outcome}

There were no significant differences in mortality, periprocedural stroke, AMI or postoperative renal function between the TAVI and SAVR groups. Postoperative onset of atrial fibrillation or flutter was more common after SAVR than after TAVI (60\% vs. $18 \%$, $\mathrm{p}<0.001)$. Erythrocytes and thrombocytes were transfused to less patients in the TAVI group $(53 \%$ vs. $78 \%, \mathrm{p}=0.026)$ and $(7 \%$ vs. $27 \% \mathrm{p}=0.021)$ respectively. Time on ventilator was longer in the TAVI group compared to the SAVR group ( $15 \pm 58 \mathrm{~h}$ vs. $12 \pm 30 \mathrm{~h}, \mathrm{p}=0.002)$. More details on clinical outcome are given in Table 3.

During the study period, there was a tendency in the TAVI group to a decrease in procedure time and ICU stay and a significant decrease in time on ventilator. The need of erythrocyte and plasma transfusion also decreased significantly. Table 4. 
C. Appel et al.

\section{Echocardiographic results}

Maximum aortic transvalvular velocity and mean aortic valve pressure gradient were significantly lower in patients undergoing TAVI $(2.3 \pm 0.4 \mathrm{~m} / \mathrm{s}$ vs. $2.6 \pm 0.5 \mathrm{~m} / \mathrm{s}, \mathrm{p}=0.002$ and $12 \pm 4 \mathrm{mmHg}$ vs. $15 \pm 5 \mathrm{mmHg}, \mathrm{p}=0.003$ ). Paravalvular regurgitation, trace to moderate, was seen in $39(87 \%)$ of the patients in the TAVI group compared with none in the SAVR group $(\mathrm{p}<0.001)$. Five $(11 \%)$ of the TAVI patients had paravalvular leakage of some hemodynamic significance, visualized as a moderate or intense Doppler signal with its origin outside the stent, at least $5 \mathrm{~mm}$ along the circumference in the short- axis view, and reaching more than 3 cm into the left ventricle.

\section{DISCUSSION}

The results of our study confirm the findings in previous studies that TAVI provides good short-term clinical outcomes in patients with high risk for mortality and morbidity after cardiac surgery $(3,5,16,17)$. These patients also present with excellent good post procedural hemodynamic results.

The two groups of patients in our study are not entirely comparable. The TAVI procedure was a new interventional technique at our center and it was predominantly considered as an alternative for patients with a high surgical risk. Therefore it was not an option to conduct a randomized study. The comparison in clinical outcomes between the TAVI and SAVR groups must be interpreted in the light of differences in baseline characteristic. However, good comparisons regarding post procedural hemodynamics could be made. 
This study shows low 30-day mortality in both groups regarding the predicted $\operatorname{logEuroSCORE.~Large~surgical~series~report~a~} 3 \%$ to $10 \%$ operative mortality for isolated SAVR in patients over 70 years of age (18-20). Furthermore, there were no differences in 30day mortality between the groups in spite of the doubled logEuroSCORE in the TAVI group.

The TAVI group had a shorter procedure time, lower incidence of postoperative atrial fibrillation and fewer patients needed erythrocyte transfusion. Still, the need of erythrocyte and plasma transfusion was higher than expected in the TAVI group. This may be related to femoral artery and apical cardiac bleeding complications and it were more than halved in the last 20 compared to the first 25 TAVI patients. Periprocedural access site complications, including minor complications, seem to be high among TAVI patients but only one patient required surgery. None of the mortalities within 30-day from surgery were directly associated $\underline{\text { to access site complications but nevertheless, even minor complications increase the }}$ procedural trauma and may affect outcome in vulnerable, high risk patients. The incidence of stroke, acute renal failure and myocardial infarction were similar to those presented in previous studies and without differences between the groups $(5,17)$.

Procedural time, ICU stay and the time on ventilator decreased over time in the TAVI group and the differences are shown in the comparison between the first 25 and the last 20 patients. This is most likely due to the learning curve of a new procedure and also to the fact that hospital guidelines stated that TAVI patients should be treated as SAVR patients postoperatively at the introduction of the TAVI procedure. 
Echocardiographic findings showed lower mean aortic pressure gradient and lower maximum transvalvular velocity in the TAVI group. The TAVI patients had lower BSA compared to the SAVR group but larger prostheses could be used at the TAVI procedure. Although the native aortic valve and annulus calcification is not excised at the TAVI procedure, the exclusion and compression of it leaves enough space for the prosthesis (21). The space occupied by the sewing ring on the prostheses used at SAVR is larger than the limitation provided by the calcification left in the annulus at TAVI.

No paravalvular regurgitation was seen in the SAVR group. However, paravalvular regurgitation was detected in a majority of the TAVI patients but seemed to be of little hemodynamic importance at in-hospital follow up. However, recent data reveals an association between late mortality and even mild paravalvular regurgitation after TAVI (22). $\underline{\text { Paravalvular leakage seems to be related to the remaining annular calcification and the TAVI }}$ prostheses, even if the frequency of it may be reduced by oversizing of the prosthesis. The impact of paravalvular regurgitation on survival must be taken in account when TAVI is considered for patients with more than short expected lifetime. Hemolysis is a well-known complication of prosthetic heart valve replacement and paravalvular regurgitation may lead to increased hemolysis. Factors like blood turbulence and high-velocity shear forces are of special importance (23). The different characteristics of how the aortic valve prostheses' are mounted in relation to clinical evident hemolytic complications need further exploration.

Scoring systems like the logEuroSCORE and the STS score are well established to predict mortality after cardiac surgery. The TAVI approach for treatment of aortic valve stenosis is less invasive and less traumatic and therefore regarded as a good option for patients with high surgical risk score. Nevertheless, the existing scoring systems may not capture all variables 
relevant in the choice of treatment for aortic valve stenosis. Obviously other factors have a strong influence on patient selection for TAVI in clinical practice(24). The patients' opinion is one of these and it is dependent on available information in general and on information provided by responsible physician. Patient selection is crucial for outcome and the specific risk factors for mortality and morbidity after TAVI have to be further clarified (25). It can not be assumed to be the same as for SAVR. It also remains to establish whether different risk evaluation system for cardiac surgery patients is appropriate for TAVI patients as well.

In conclusion, TAVI offers a safe short-term treatment with excellent good hemodynamic results in selected patients with high-risk for SAVR. Besides high logEuroSCORE, other factors influence the choice of therapy. In order to offer our patients the best treatment for aortic stenosis, comparisons between TAVI and SAVR regarding short and long term outcome and risk factors must continuously proceed. In addition, the selection criteria for TAVI need to be refined and evaluated. The issue of paravalvular leakage and valve durability need to be addressed and may influence the patient selection.

\section{Acknowledgements}

The study was supported by The Swedish Heart and Lung Foundation, Medical Research Council of Southeast Sweden (FORSS), ALF Grants, County Council of Östergötland. Special thanks to Inger Huljebrant and Miriam Johansson.

\section{Declaration of interest:}

The authors report no conflict of interest. The authors alone are responsible for the content and writing of the paper. 


\section{Footnote}

This paper has partly been presented at the 60th Annual Meeting of the Scandinavian

Association for Thoracic Surgery in Tampere, Finland, 18 - 20 August 2011.

\section{References}

1. Carabello BA, Paulus WJ. Aortic stenosis. Lancet. 2009;373:956-66.

2. Bonow RO, Carabello BA, Chatterjee K, de Leon AC, Jr., Faxon DP, Freed MD, et al. 2008 Focused update incorporated into the ACC/AHA 2006 guidelines for the management of patients with valvular heart disease: a report of the American College of Cardiology/American Heart Association Task Force on Practice Guidelines. Circulation 2008;118:e523-661.

3. Wenaweser P, Pilgrim T, Kadner A, Huber C, Stortecky S, Buellesfeld L, et al. Clinical outcomes of patients with severe aortic stenosis at increased surgical risk according to treatment modality. J Am Coll Cardiol 201;58:2151-62.

4. Astor BC, Kaczmarek RG, Hefflin B, Daley WR. Mortality after aortic valve replacement: results from a nationally representative database. Ann Thorac Surg 2000;70:1939-45.

5. Smith CR, Leon MB, Mack MJ, Miller DC, Moses JW, Svensson LG, et al. Transcatheter versus surgical aortic-valve replacement in high-risk patients. N Engl J Med 2011;364:2187-98.

6. Vanky FB, Hakanson E, Svedjeholm R. Long-term consequences of postoperative heart failure after surgery for aortic stenosis compared with coronary surgery. Ann Thorac Surg 2007;83:2036-43.

7. Florath I, Rosendahl UP, Mortasawi A, Bauer SF, Dalladaku F, Ennker IC, et al. Current determinants of operative mortality in 1400 patients requiring aortic valve replacement. Ann Thorac Surg 2003;76:75-83.

8. Iung B, Cachier A, Baron G, Messika-Zeitoun D, Delahaye F, Tornos P, et al. Decisionmaking in elderly patients with severe aortic stenosis: why are so many denied surgery? Eur Heart J 2005;26:2714-20.

9. Al-Attar N, Himbert D, Descoutures F, Iung B, Raffoul R, Messika-Zeitoun D, et al. Transcatheter aortic valve implantation: selection strategy is crucial for outcome. Ann Thorac Surg 2009;87:1757-62.

10. Cribier A, Eltchaninoff H, Bash A, Borenstein N, Tron C, Bauer F, et al. Percutaneous transcatheter implantation of an aortic valve prosthesis for calcific aortic stenosis: first human case description. Circulation 2002;106:3006-8.

11. Masson JB, Kovac J, Schuler G, Ye J, Cheung A, Kapadia S, et al. Transcatheter aortic valve implantation: review of the nature, management, and avoidance of procedural complications. J Am Coll Cardiol 2009;2:811-20.

12. Michel P, Roques F, Nashef SA. Logistic or additive EuroSCORE for high-risk patients? Eur J Cardiothorac Surg 2003;23:684-7. 
13. Webb JG, Chandavimol M, Thompson CR, Ricci DR, Carere RG, Munt BI, et al. Percutaneous aortic valve implantation retrograde from the femoral artery. Circulation 2006;113:842-50.

14. Ye J, Cheung A, Lichtenstein SV, Carere RG, Thompson CR, Pasupati S, et al. Transapical aortic valve implantation in humans. J Thorac Cardiovasc Surg 2006;131:1194-6.

15. Baranowski J, Ahn H, Freter W, Nielsen NE, Nylander E, Janerot-Sjoberg B, et al. Echoguided presentation of the aortic valve minimises contrast exposure in transcatheter valve recipients. Catheter Cardiovasc Interv 2011;77:272-5.

16. Moat NE, Ludman P, de Belder MA, Bridgewater B, Cunningham AD, Young CP, et al. Long-Term Outcomes After Transcatheter Aortic Valve Implantation in High-Risk Patients With Severe Aortic Stenosis: The U.K. TAVI Registry. J Am Coll Cardiol 2011;58:2130-8.

17. Nielsen HH, Thuesen L, Egeblad H, Poulsen SH, Klaaborg KE, Jakobsen CJ, et al. Single center experience with transcatheter aortic valve implantation using the Edwards SAPIEN Valve. Scand Cardiovasc J 2011;45:261-6.

18. Florath I, Albert A, Boening A, Ennker IC, Ennker J. Aortic valve replacement in octogenarians: identification of high-risk patients. Eur J Cardiothorac Surg 2010;37:130410 .

19. Kesavan S, Iqbal A, Khan Y, Hutter J, Pike K, Rogers C, et al. Risk profile and outcomes of aortic valve replacement in octogenarians. World J Cardiol 2011;3:359-66.

20. Langanay T, Flecher E, Fouquet O, Ruggieri VG, Tour Bde L, Felix C, et al. Aortic valve replacement in the elderly: the real life. Ann Thorac Surg 2012;93:70-8.

21. Webb JG, Pasupati S, Humphries K, Thompson C, Altwegg L, Moss R, et al. Percutaneous transarterial aortic valve replacement in selected high-risk patients with aortic stenosis. Circulation 2007;116:755-63.

22. Kodali SK, Williams MR, Smith CR, Svensson LG, Webb JG, Makkar RR, et al. TwoYear Outcomes after Transcatheter or Surgical Aortic-Valve Replacement. N Engl J Med 2012;336:1686-95 in press.

23. Safi AM, Kwan T, Afflu E, Al Kamme A, Salciccioli L. Paravalvular regurgitation: a rare complication following valve replacement surgery. Angiology 2000;51:479-87.

24. Stortecky S, Brinks H, Wenaweser P, Huber C, Pilgrim T, Windecker S, et al. Transcatheter aortic valve implantation or surgical aortic valve replacement as redo procedure after prior coronary artery bypass grafting. Ann Thorac Surg 2011;92:1324-30.

25. Hayashida K, Lefevre T, Chevalier B, Hovasse T, Romano M, Garot P, et al. Transfemoral aortic valve implantation new criteria to predict vascular complications. J Am Coll Cardiol 2011;4:851-8. 
C. Appel et al.

Table 1. Factors influencing the choice of TAVI for patients with logEuroSCORE $<15 \%$.

Indications for TAVI n

Logistic EuroSCORE $>15 \%$

Logistic EuroSCORE <15\%

Patient's opinion

Previous cardiac surgery

Fragile patient

Age $>90$ years

Heavily calcified aorta

Immunosupressive treatment

Sequelae of chest radiotherapy

Cancer, scheduled for surgery

Cold agglutinin disease

Poor renal function

Poor pulmonary function $\mathbf{n}$ 16

29

10

6

6

3

3

2

2

1

1

1

1 
C. Appel et al.

Table 2. Baseline characteristics of the patients.

TAVI $n=45 \quad$ SAVR $n=45 \quad p$-value

\begin{tabular}{lrrr}
\hline Age (years) & $81 \pm 8$ & $77 \pm 5$ & 0.005 \\
Female gender & $23(51)$ & $23(51)$ & 1.0 \\
Logistic EuroSCORE (\%) & $16 \pm 11$ & $8 \pm 4$ & $<0.001$ \\
STS score & $4.4 \pm 2.2$ & $3.0 \pm 1.3$ & 0.001 \\
Body mass index $\left(\mathrm{kg} / \mathrm{m}^{2}\right)$ & $25 \pm 5$ & $27 \pm 4$ & 0.007 \\
Body surface area $\left(\mathrm{m}^{2}\right)$ & $1.8 \pm 0.2$ & $1.9 \pm 0.2$ & 0.02 \\
Insulin or orally treated diabetes mellitus & $8(18)$ & $8(18)$ & 1.0 \\
Chronic obstructive pulmonary disease & $3(7)$ & $3(7)$ & 1.0 \\
Cerebrovascular disease & $7(16)$ & $5(11)$ & 0.8 \\
Peripheral artery disease & $8(18)$ & $4(9)$ & 0.4 \\
Hypertension & $28(62)$ & $26(58)$ & 0.8 \\
Preoperative atrial fibrillation & $10(22)$ & $3(7)$ & 0.07 \\
Angina pectoris & $7(16)$ & $10(22)$ & 0.6 \\
NYHA II & $6(13)$ & $8(18)$ & 0.8 \\
NYHA III & $37(82)$ & $37(82)$ & 1.0 \\
\hline
\end{tabular}




\begin{tabular}{|c|c|c|c|}
\hline NYHA IV & $1(2)$ & $0(0)$ & 1.0 \\
\hline History of congestive heart failure & $15(33)$ & $6(13)$ & 0.04 \\
\hline LVEF normal (>50\%) & $32(71)$ & $39(87)$ & 0.1 \\
\hline LVEF mildly impaired (40-49\%) & $10(22)$ & $3(7)$ & 0.07 \\
\hline LVEF moderately impaired (30-39\%) & $2(4)$ & $3(7)$ & 1.0 \\
\hline LVEF severely impaired $(<30 \%)$ & $1(2)$ & $0(0)$ & 1.0 \\
\hline Glomerular filtration rate $<60 \mathrm{ml} / \mathrm{min}$ & $31(69)$ & $25(56)$ & 0.3 \\
\hline Plasma Creatinine $>200 \mu \mathrm{mol} / \mathrm{L}$ & $2(4)$ & $0(0)$ & 0.5 \\
\hline Systolic pulmonary artery pressure $>60 \mathrm{mmHg}$ & $9(20)$ & $4(9)$ & 0.2 \\
\hline Previous cardiac surgery & $14(31)$ & $1(2)$ & $<0.001$ \\
\hline Previous CABG & $9(20)$ & $0(0)$ & 0.003 \\
\hline Previous SAVR & $2(4)$ & $0(0)$ & 0.5 \\
\hline Previous myocardial infarction & $13(29)$ & $4(9)$ & 0.03 \\
\hline Previous percutaneous coronary intervention & $12(27)$ & $1(2)$ & 0.002 \\
\hline Mitral regurgitation - moderate & $4(9)$ & $3(7)$ & 0.7 \\
\hline Mitral regurgitation - severe & $1(2)$ & $1(2)$ & 1.0 \\
\hline Tricuspid valve regurgitation - moderate & $9(20)$ & $6(15)$ & 0.6 \\
\hline Tricuspid valve regurgitation - severe & $1(2)$ & $0(0)$ & 1.0 \\
\hline Maximal aortic transvalvular velocity $(\mathrm{m} / \mathrm{s})$ & $4.7 \pm 0.8$ & $4.8 \pm 0.8$ & 0.3 \\
\hline Mean aortic valve pressure gradient $(\mathrm{mmHg})$ & $55 \pm 20$ & $56 \pm 19$ & 0.6 \\
\hline Aortic valve area $\left(\mathrm{cm}^{2}\right)$ & $0.55 \pm 0.16$ & $0.62 \pm 0.15$ & 0.009 \\
\hline
\end{tabular}

Results are given as $\mathrm{n}(\%)$ or as mean $\pm \mathrm{SD} . \mathrm{CABG}=$ Coronary artery bypass grafting; LVEF $=$ Left ventricular ejection fraction; NYHA = New York Heart Association class; SAVR = 
C. Appel et al.

surgical aortic valve replacement; STS = Society of Thoracic Surgeons; TAVI = transcatheter aortic valve replacement.

Table 3. Mortality and postprocedural, intrahospital outcome.

\begin{tabular}{lrrr}
\hline & TAVI n=45 & SAVR $\mathbf{n = 4 5}$ & p-value \\
\hline 30-day mortality & $3(7)$ & $2(4)$ & 1.0 \\
6-month mortality & $5(11)$ & $2(4)$ & 0.4 \\
Myocardial infarction & $1(2)$ & $1(2)$ & 1.0 \\
Plasma-ASAT, day 1 ( $\mu$ kat/L) & $0.95 \pm 0.86$ & $1.38 \pm 1.18$ & $<0.001$ \\
Plasma-ALAT, day1 ( $\mu$ kat/L) & $0.50 \pm 0.76$ & $0.71 \pm 0.90$ & 0.03 \\
Plasma-CK-MB, day 1 $(\mu \mathrm{g} / \mathrm{L})$ & $20.54 \pm 17.99$ & $25.89 \pm 20.08$ & 0.05 \\
Plasma-TroponinT, day 3-4 ( $\mu \mathrm{g} / \mathrm{L})$ & $0.46 \pm 0.46$ & $0.58 \pm 0.81$ & 0.1 \\
Stroke & $1(2)$ & $1(2)$ & 1.0 \\
Plasma Creatinine elevation $>50 \%$ & $4(9)$ & $5(11)$ & 1.0 \\
Dialysis & $3(7)$ & $0(0)$ & 0.2 \\
Atrial fibrillation or flutter $(\mathrm{postop}$. onset) & $8(18)$ & $27(60)$ & $<0.001$ \\
Pneumonia & $2(4)$ & $1(2)$ & 1.0 \\
Septicaemia & $0(0)$ & $0(0)$ & 1.0 \\
Multiorgan failure & $1(2)$ & $1(2)$ & 1.0
\end{tabular}


C. Appel et al.

Erythrocyte transfusion

Erythrocyte transfusion* $(\mathrm{mL})$

Plasma transfusion

Plasma transfusion* $(\mathrm{mL})$

Thrombocyte transfusion

Thrombocyte transfusion* $(\mathrm{mL})$

Procedure time (min)

ICU-stay (h)

Time on ventilator $(\mathrm{h})$

Reoperation due to tamponade/bleeding

Reoperation due to sternal infection

Reoperation due to valvular dysfunction

Reoperation due to femoral artery occlusion

Reoperation due to cardiac arrest
$24(53)$

$1182 \pm 864$

$28(62)$

$1167 \pm 1172$

$3(7)$

$267 \pm 14$

$127 \pm 42$

$37 \pm 61$

$15 \pm 58$

$1(2)$

$0(0)$

$0(0)$

$1(2)$

$0(0)$
$35(78)$

$923 \pm 633$

$21(47)$

$970 \pm 828$

0.5

$$
12(27) \quad 0.02
$$

$323 \pm 121$

0.3

$179 \pm 58<0.001$

$31 \pm 37$

1.0

$12 \pm 30 \quad 0.002$

4 (9)

0.4

2 (4)

0.5

$0(0)$

1.0

$0(0)$

1.0

$1(2)$

1.0

Results are given as $\mathrm{n}(\%)$ or as mean $\pm \mathrm{SD} . *$ Average volume given to patients who received transfusion. ASAT=Aspartate aminotransferase; ALAT=Alanine aminotransferase; CK$\mathrm{MB}=$ Creatine kinase-muscle, brain isotype; $\mathrm{ICU}=$ Intensive care unit; SAVR = surgical aortic valve replacement; TAVI $=$ transcatheter aortic valve replacement. 
C. Appel et al.

Table 4. The first 25 compared to the last 20 TAVI patients.

\begin{tabular}{lrrr}
\hline & firstTAVI n=25 & lastTAVI n=20 & p-value \\
\hline Procedure time (min) & $138 \pm 46$ & $113 \pm 36$ & 0.07 \\
ICU-stay (h) & $49 \pm 79$ & $21 \pm 15$ & 0.08 \\
Time on ventilator (h) & $24 \pm 77$ & $2 \pm 2$ & 0.02 \\
Plasma Creatinine elevation $>50 \%$ & $4(16)$ & $0(0)$ & 0.1 \\
Erythrocyte transfusion & $17(68)$ & $7(35)$ & 0.04 \\
Plasma transfusion & $20(80)$ & $7(35)$ & 0.005 \\
Thrombocyte transfusion & $2(8)$ & $1(5)$ & 1.0 \\
\hline
\end{tabular}

Results are given as $\mathrm{n}(\%)$ or as mean \pm SD. ICU=Intensive care unit; TAVI $=$ transcatheter aortic valve replacement. 